\title{
Linfohistiocitose Hemofagocítica Secundária a Infeção por Epstein-Barr: Raridade e Gravidade num Adulto Imunocompetente
}

\author{
Epstein-Barr Virus-Associated Hemophagocytic \\ Lymphohistiocytosis: Rarity and Severity in an \\ Immunocompetent Adult
}

\author{
Andreia COSTA $\triangle^{1}$, Anusca PAIXÃO ${ }^{1}$, Henrique SANTOS ${ }^{2}$, Fernando SALVADOR ${ }^{1}$ \\ Acta Med Port 2019 Jan;32(1):78-80 • https://doi.org/10.20344/amp.9474
}

\section{RESUMO}

A linfohistiocitose hemofagocítica é uma entidade clínica rara, agressiva e que pode colocar em risco a vida do doente, caraterizada por uma ativação imune excessiva. É desencadeada por vários estímulos, em que as infeções desempenham um papel importante. O estímulo infecioso mais comum é a infeção viral, especialmente por Epstein-Barr. As alterações da coagulação são comuns na linfohistiocitose hemofagocítica e a coagulação intravascular disseminada pode estar presente nos casos graves. Apresentamos um caso clínico de linfohistiocitose hemofagocítica secundária a infeção por Epstein-Barr, complicada com coagulação intravascular disseminada, que evoluiu favoravelmente apenas com tratamento de suporte e sem necessidade de tratamento específico.

Palavras-chave: Choque Séptico; Coagulação Intravascular Disseminada; Hospedeiro Imunocomprometido; Infecções por Vírus Epstein-Barr; Linfohistiocitose Hemofagocítica

\section{ABSTRACT}

Hemophagocytic lymphohistiocytosis is a rare, aggressive and life-threatening syndrome, characterized by an excessive immune activation. It is triggered by multiple stimuli, with infections having an important role. The most common infectious trigger is viral infection, particularly by Epstein-Barr virus. Coagulation disorders are common in hemophagocytic lymphohistiocytosis and disseminated intravascular coagulation can be present in severe cases. We report a clinical case of Epstein-Barr virus-associated hemophagocytic lymphohistiocytosis, complicated with disseminated intravascular coagulation which evolved favorably with only supportive therapy and without specific treatment.

Keywords: Disseminated Intravascular Coagulation; Epstein-Barr Virus Infections; Immunocompromised Host; Lymphohistiocytosis, Hemophagocytic; Shock, Septic

\section{INTRODUÇÃO}

A linfohistiocitose hemofagocítica (HLH) é uma entidade clínica rara, mas potencialmente fatal, caraterizada por uma ativação imune excessiva. Pode ser primária, associada a anomalias genéticas, ou secundária a vários estímulos (HLH adquirida), em que as infeções desempenham um papel importante, a par das doenças autoimunes e neoplásicas, sobretudo hematológicas. O diagnóstico baseia-se em achados clínicos e laboratoriais: febre, esplenomegalia, citopenias, hipertrigliceridémia, hiperferritinémia, hemofagocitose, atividade diminuída das células natural killer (NK), aumento dos CD25 solúveis. ${ }^{1-3}$

A apresentação clínica variada e a inespecificidade dos achados clínicos e laboratoriais conduzem a um atraso no diagnóstico, sendo essencial um alto grau de suspeição. ${ }^{2,3}$

$O$ vírus Epstein-Barr (EBV) é o vírus mais consistentemente associado à HLH, como uma infeção de novo ou reativação de infeção latente..$^{3,4}$

A coagulação intravascular disseminada (CID) carateriza-se por uma ativação sistémica da coagulação, resultando em trombose de vasos de pequeno e médio calibre, disfunção multiorgânica e eventos hemorrágicos graves.
Pode resultar de várias condições, destacando-se as infeções graves e as neoplasias. O diagnóstico e tratamento devem ter em conta a etiologia subjacente. ${ }^{5,6}$

\section{CASO CLÍNICO}

Apresenta-se o caso de uma doente do sexo feminino, 54 anos, que recorreu ao serviço de urgência por desconforto no hipocôndrio direito, icterícia, colúria e febre com uma semana de evolução. Não apresentava dados epidemiológicos de relevo, mas havia referência a sintomas sugestivos de infeção vírica, com odinofagia e mialgias, cerca de 3 - 4 semanas antes, tendo-se automedicado com analgésico e anti-inflamatório, com melhoria clínica apenas parcial.

Objetivamente, apresentava-se hipotensa (pressão arterial 74/51 mmHg), taquicárdica (frequência cardíaca 115 bpm) e febril (temperatura auricular $39^{\circ} \mathrm{C}$ ), com abdómen doloroso de forma difusa à palpação, mais evidente no hipocôndrio direito.

No estudo analítico, havia a salientar pancitopenia, elevação dos parâmetros inflamatórios, lesão renal aguda,

1. Serviço de Medicina Interna. Centro Hospitalar de Trás-os-Montes e Alto Douro. Vila Real. Portugal.

2. Serviço de Medicina Intensiva. Centro Hospitalar de Trás-os-Montes e Alto Douro. Vila Real. Portugal.

$\triangle$ Autor correspondente: Andreia Costa. andreia_inha2@hotmail.com

Recebido: 22 de julho de 2017 - Aceite: 20 de setembro de 2018 | Copyright @ Ordem dos Médicos 2019 
Tabela 1 - Resultados analíticos ao longo do internamento e no seguimento em consulta externa

\begin{tabular}{|c|c|c|c|c|c|}
\hline \multicolumn{6}{|l|}{ Resultados de testes laboratoriais } \\
\hline & $\begin{array}{c}\text { À admissão } \\
(30 / 01 / 17)\end{array}$ & $\begin{array}{l}\text { Serviço } \\
\text { Medicina } \\
(03 / 02 / 17)\end{array}$ & $\begin{array}{c}\text { À data de alta } \\
(08 / 02 / 17)\end{array}$ & $\begin{array}{l}\text { Consulta } \\
\text { Externa } \\
(13 / 03 / 17)\end{array}$ & $\begin{array}{c}\text { Consulta } \\
\text { Externa } \\
(15 / 05 / 17)\end{array}$ \\
\hline Hemoglobina (g/dL) & 11,46 & 9,3 & 9,06 & 11,53 & 12,93 \\
\hline Leucócitos (cél/uL) & 2100 & 2900 & 3000 & 2200 & 4100 \\
\hline Plaquetas (cél/uL) & 22000 & 111000 & 421000 & 234000 & 201000 \\
\hline Proteína C reativa $(\mathrm{mg} / \mathrm{dL})$ & 16,9 & 3,2 & 0,6 & 0,1 & 0,1 \\
\hline Ureia (mg/dL) & 84 & 31 & 17 & 30 & 37 \\
\hline Creatinina (mg/dL) & 2,2 & 0,5 & 0,3 & 0,4 & 0,5 \\
\hline Aspartato aminotransferase (U/L) & 457 & 282 & 55 & 39 & 33 \\
\hline Alanina aminotransferase (U/L) & 182 & 201 & 62 & 44 & 29 \\
\hline Gama glutamiltransferase (U/L) & 268 & 748 & 561 & 68 & 30 \\
\hline Fosfatase alcalina (U/L) & 252 & 481 & 330 & 86 & 97 \\
\hline Bilirrubina total (mg/dL) & 4,8 & 3,4 & 1,4 & 0,6 & 0.3 \\
\hline Bilirrubina direta (mg/dL) & 3,6 & 3,1 & 1,0 & 0,3 & 0.1 \\
\hline Lactato desidrogenase (U/L) & 3530 & 1670 & 534 & 175 & 171 \\
\hline
\end{tabular}

citocolestase hepática com hiperbilirrubinémia direta e lactato desidrogenase $3803 \mathrm{U} / \mathrm{L}$. (Tabela 1).

Perante a gravidade da situação clínica, com disfunção multiorgânica, nomeadamente renal, hematológica, hepática e cardiovascular, com instabilidade hemodinâmica e necessidade de suporte aminérgico, foi admitida em unidade de cuidados intensivos, considerando-se nesta fase a hipótese de um choque séptico com provável ponto de partida abdominal, nomeadamente numa colangite/colecistite/hepatite, para o qual iniciou antibioterapia empírica.

No primeiro dia de internamento evoluiu com edema agudo do pulmão e insuficiência respiratória, com necessidade de suporte ventilatório não invasivo, ao qual respondeu favoravelmente.

O estudo analítico realizado revelou haptoglobina diminuída, esfregaço de sangue periférico sem alterações, prova de Coombs e pesquisa de esquizócitos negativos, e alteração da coagulação (aumento do tempo de protrombi- na e de tromboplastina parcial ativado, d-dímeros aumentados, fibrinogénio diminuído), tendo-se assumido coagulação intravascular disseminada secundária a sépsis, sem diátese hemorrágica.

Assistiu-se a uma evolução favorável, de forma gradual, a partir do segundo dia de internamento, com melhoria sintomática, apirexia sustentada e progressivo desmame ventilatório e aminérgico.

Concomitantemente foi constatada hiperferritinémia (72010 ng/mL) e hipertrigliceridémia (432 mg/dL). Perante a suspeita de linfohistiocitose hemofagocítica (HLH), realizou mielograma que revelou aumento dos macrófagos com hemofagocitose (Fig. 1).

O estudo autoimune foi negativo, assim como as serologias (vírus hepatite $B, C$ e E, imunodeficiência humana 1 e 2 , herpes simplex, herpes vírus humano 6 , parvovírus, citomegalovírus, adenovírus, echovírus, Wright, rosa bengala, leptospira, toxoplasma) com exceção do teste Paul Bunnel
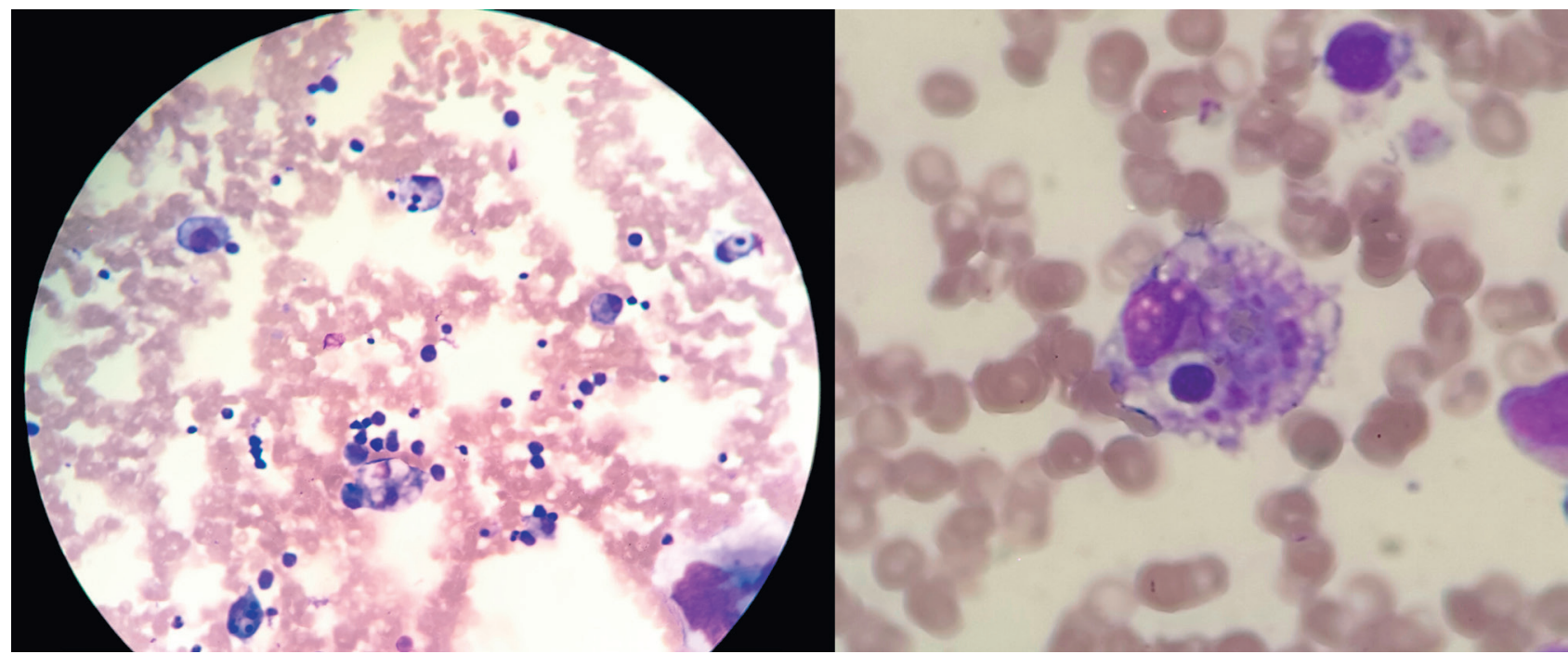

Figura 1 - Hemofagocitose na medula óssea (mielograma) 
que foi positivo, confirmado posteriormente com a quantificação da carga vírica no valor de $11500 \mathrm{UI} / \mathrm{mL}$. A pesquisa de influenza foi negativa.

Na citometria de fluxo constatou-se diminuição da subpopulação linfocitária NK e na imunofenotipagem alterações reativas provavelmente secundárias ao EBV. O estudo genético para linfohistiocitose hemofagocítica primária, que incluiu um painel de 10 genes (AP3B2, BLOC1S6, LYST, PRF1, RAB27A, SH2D1A, STX11, STXBP2, UNC13D e $X I A P)$ foi negativo.

Cumpriam-se assim seis em oito critérios HLH 2004 para HLH secundária a EBV.

Após discussão em reunião multidisciplinar e dada a evolução favorável, optou-se por tratamento de suporte, protelando-se a introdução de terapêutica específica (nomeadamente, imunoglobulina humana ou rituximabe).

Durante o internamento, evoluiu favoravelmente, com desmame progressivo de oxigenoterapia e melhoria das alterações analíticas.

Teve alta, clínica e laboratorialmente melhorada, orientada para a consulta externa, onde se mantém ao fim de quatro meses assintomática e sem alterações analíticas de relevo (Tabela 1 ).

\section{DISCUSSÃO}

O diagnóstico de HLH pode passar despercebido dado a inespecificidade dos achados clínicos e laboratoriais. Perante uma sépsis com disfunção multiorgânica, sem etiologia clara, esta hipótese deve ser levantada, dado que a patofisiologia da resposta inflamatória sistémica é similar à da HLH e é necessário um alto grau de suspeição para os diferenciar. A elevação marcada da ferritina pode ser um dos achados laboratoriais mais precoces e sugerir esta patologia. ${ }^{1-4}$

Quando não tratada, é frequentemente fatal. No sentido de melhorar a sobrevida, é essencial um diagnóstico precoce e tratamento adequado. . $^{3,4}$

Existem vários casos publicados de HLH a EBV. Nos doentes instáveis ou com deterioração progressiva é recomendado o início precoce de tratamento específico, nomeadamente dexametasona e etoposídeo ou rituximabe, concomitantemente ao tratamento da etiologia subjacente. A literatura sugere que a introdução precoce (primeiras quatro semanas) de etoposídeo aumenta a sobrevida a lon-

\section{REFERÊNCIAS}

1. Kleynberg R, Schiller G. Secondary hemophagocytic lymphohistiocytosis in adults: an update on diagnosis and therapy. Clin Adv Hematol Oncol. 2012;10:726-32.

2. Rosado FG, Kim AS. Hemophagocytic lymphohistiocytosis: an update on diagnosis and pathogenesis. Am J Clin Pathol. 2013;139:713.

3. McClain KL. Clinical features and diagnosis of hemophagocytic lymphohistiocytosis. Up to date [consultado 2017 maio 21] Disponível em: http://www.uptodate.com

4. George MR. Hemophagocytic lymphohistiocytosis: review of etiologies and management. J Blood Med. 2014;5:69-86.

5. Wada H, Matsumoto T, Yamashita Y. Diagnosis and treatment of disseminated intravascular coagulation (DIC) according to four DIC guidelines. J Intensive Care. 2014;2:15-22.

6. Levi M, Toh $\mathrm{CH}$, Thachil J, Watson HG. Guidelines for the diagnosis go prazo. O transplante de células hematopoiéticas pode ser necessário nos casos refratários. . $^{3,7}$

A decisão de atrasar ou mesmo de não iniciar este tipo de tratamento aos pacientes que estão a melhorar clinicamente, acaba por ser difícil e nem sempre linear. Por outro lado, existem casos relatados de evolução favorável sem necessidade de recorrer a estes tratamentos específicos que apresentam efeitos tóxicos importantes. ${ }^{7,8}$

As alterações da coagulação são comuns na HLH, ocorrendo em mais de metade dos casos, podendo associar-se a pior prognóstico devido às complicações hemorrágicas. A coagulação intravascular disseminada ocorre nos casos mais graves. ${ }^{9}$

Neste caso em particular, para além da citocolestase secundária a infeção por EBV, destaca-se a gravidade e a raridade da HLH num adulto imunocompetente. A associação ao vírus EBV é mais frequentemente observada em crianças/adolescentes e adultos jovens.

Destaca-se, neste caso, a evolução favorável apenas com tratamento de suporte, sem necessidade de tratamento específico ou etiológico, e a associação concomitante a coagulação intravascular disseminada.

\section{PROTEÇÃO DE PESSOAS E ANIMAIS}

Os autores declaram que os procedimentos seguidos estavam de acordo com os regulamentos estabelecidos pelos responsáveis da Comissão de Investigação Clínica e Ética e de acordo com a Declaração de Helsínquia da Associação Médica Mundial.

\section{CONFIDENCIALIDADE DOS DADOS}

Os autores declaram ter seguido os protocolos do seu centro de trabalho acerca da publicação de dados.

\section{CONSENTIMENTO DO DOENTE}

Obtido.

\section{CONFLITOS DE INTERESSE}

Os autores declaram não terem qualquer conflito de interesse relativamente ao presente artigo.

\section{FONTES DE FINANCIAMENTO}

Não existiram subsídios ou bolsas que tenham contribuído para a realização do trabalho.

and management of disseminated intravascular coagulation. British Committee for Standards in Haematology. Br J Haematol. 2009;145:2433.

7. Imashuku S. Treatment of Epstein-Barr virus-related hemophagocytic lymphohistiocystosis (EBV-HLH); Update 2010. J Pediatr Hematol Oncol. 2011;33:35-9.

8. Belyea B, Hinson A, Moran C, Hwang E, Heath J, Barfield R. Spontaneous resolution of Epstein-Barr virus-associated hemophagocytic lymphohistiocytosis. Pediatr Blood Cancer. 2010;55:754-6.

9. Valade S, Azoulay E, Galicier L, Boutboul D, Zafrani L, Stepanian A, et al. Coagulation disorders and bleedings in critically ill patients with hemophagocytic lymphohistiocytosis. Observational study. Medicine. 2015;94:e1692. 